\title{
Effects of moderate global maternal nutrient reduction on fetal baboon renal mitochondrial gene expression at 0.9 gestation
}

\author{
Susana P. Pereira, ${ }^{1,2,3}$ Paulo J. Oliveira, ${ }^{1}$ Ludgero C. Tavares, ${ }^{1,2}$ António J. Moreno, ${ }^{2}$ Laura A. Cox, ${ }^{4}$ \\ Peter W. Nathanielsz, ${ }^{3}$ and Mark J. Nijland ${ }^{3}$ \\ ${ }^{1}$ Center for Neuroscience and Cell Biology, University of Coimbra, Coimbra, Portugal; ${ }^{2}$ Department of Life Sciences, School \\ of Sciences and Technology, University of Coimbra, Coimbra, Portugal; ${ }^{3}$ Center for Pregnancy and Newborn Research, \\ University of Texas Health Science Center, San Antonio, Texas; and ${ }^{4}$ Department of Genetics, Texas Biomedical Research \\ Institute, San Antonio, Texas
}

Submitted 25 July 2014; accepted in final form 4 March 2015

Pereira SP, Oliveira PJ, Tavares LC, Moreno AJ, Cox LA, Nathanielsz PW, Nijland MJ. Effects of moderate global maternal nutrient reduction on fetal baboon renal mitochondrial gene expression at 0.9 gestation. Am J Physiol Renal Physiol 308: F1217-F1228, 2015. First published March 11, 2015; doi:10.1152/ajprenal.00419.2014.-Early life malnutrition results in structural alterations in the kidney, predisposing offspring to later life renal dysfunction. Kidneys of adults who were growth restricted at birth have substantial variations in nephron endowment. Animal models have indicated renal structural and functional consequences in offspring exposed to suboptimal intrauterine nutrition. Mitochondrial bioenergetics play a key role in renal energy metabolism, growth, and function. We hypothesized that moderate maternal nutrient reduction (MNR) would adversely impact fetal renal mitochondrial expression in a well-established nonhuman primate model that produces intrauterine growth reduction at term. Female baboons were fed normal chow diet or $70 \%$ of control diet (MNR). Fetal kidneys were harvested at cesarean section at 0.9 gestation (165 days gestation). Human Mitochondrial Energy Metabolism and Human Mitochondria Pathway PCR Arrays were used to analyze mitochondrially relevant mRNA expression. In situ protein content was detected by immunohistochemistry. Despite the smaller overall size, the fetal kidney weight-to-body weight ratio was not affected. We demonstrated fetal sex-specific differential mRNA expression encoding mitochondrial metabolite transport and dynamics proteins. MNRrelated differential gene expression was more evident in female fetuses, with 16 transcripts significantly altered, including 14 downregulated and 2 upregulated transcripts. MNR impacted 10 transcripts in male fetuses, with 7 downregulated and 3 upregulated transcripts. The alteration in mRNA levels was accompanied by a decrease in mitochondrial protein cytochrome $c$ oxidase subunit VIc. In conclusion, transcripts encoding fetal renal mitochondrial energy metabolism proteins are nutrition sensitive in a sex-dependent manner. We speculate that these differences lead to decreased mitochondrial fitness that contributes to renal dysfunction in later life.

mitochondria; kidney; fetal programming; nonhuman primate; gene expression

SUBOPTIMAL PRENATAL DEVELOPMENT predisposes to adult onset diseases such as hypertension, diabetes, cardiovascular, and renal disease $(2,9,42,64)$. Importantly, there is clear evidence that the developing nonhuman primate kidney is sensitive to decreased maternal nutrition (45). Poor intrauterine nutrition is associated with reduced nephron number in both animals and humans $(29,35,41,62)$. Analysis of renal autopsies of adults

Address for reprint requests and other correspondence: P. J. Oliveira, Center for Neuroscience and Cell Biology, UC Biotech Bldg., Lot 8A, Biocant Park, Univ. of Coimbra, Cantanhede 3060-197, Portugal (e-mail: pauloliv@cnc.uc.pt). born with low birth weight has shown substantial variations in renal composition (26). Remarkably, little attention has been given to the possible involvement of mitochondria as putative mediators between maternal nutrient reduction (MNR) and altered renal development in their offspring. This is surprising because healthy nephron and organ function rely on polarized mitochondria abundant in epithelial cells (24). Mitochondria not only produce energy using the oxidative phosphorylation system (OXPHOS) but are also a source of GTP and amino acids, the hub of cell death signaling pathways, a reservoir of cell $\mathrm{Ca}^{2+}$, and an important site for the production of ROS (38, 48-50). Mitochondria also play a crucial role in numerous regulatory functions during oocyte maturation (12), fertilization, and the initiation and progression of preimplantation embryos (16). A postmortem study (25) of muscles from premature neonates demonstrated a functional respiratory chain showing that mitochondria are functional during fetal development.

Dysfunctional mitochondrial OXPHOS is a key player in a variety of human disorders including primary mitochondrial diseases caused by mutations in mitochondrial and/or nuclear DNA (14) as well as in aging (4), drug toxicity (19, 30, 48, 49), diabetes (58), and several neurodegenerative disorders (34). Both the quality and quantity of mitochondria are essential prerequisites for successful embryo and fetal development (59). For all these reasons, we propose that the regulation of mitochondrial metabolism during fetal development is not only important for neonatal life but also may have implications for health and disease in adulthood.

Baboons are valuable models for the study of complex physiological and disease processes because they exhibit similarity to human health and disease phenotypes. The baboon also exhibits a pattern of disease susceptibility and health complications that is very similar to that seen in humans (53). Our previous study (31) demonstrated that pregnant baboons that consumed $70 \%$ of the global ad libitum diet from 0.16 to 0.5 gestation had an $11 \%$ decrease in maternal body weight accompanied by intrauterine growth reduction (IUGR) and a similar decrease in fetal body weight, whereas the fetal body weight-to-kidney weight ratio was not significantly altered. However, this moderate level of MNR altered the subcellular histology of the kidney at $50 \%$ gestation by decreasing tubule density and altering renal transcriptome expression, with several transcripts for mitochondrial components being downregulated, including subunits of the respiratory chain and ATP synthase $(11,45)$. 
In accordance with these previous observations, the aim of the present study was to determine the effects of controlled and moderate global MNR on fetal baboon renal mitochondrial transcripts and proteins at term (0.9 gestation). We hypothesized that poor maternal nutrition during pregnancy impairs the mitochondrial transcriptome, potentially influencing kidney development and contributing to the development of renal disease in adult life.

\section{MATERIALS AND METHODS}

Ethical approval. All animal procedures, including pain relief, were approved by the Animal Care and Use Committees of the Texas Biomedical Research Institute and University of Texas Health Science Center (San Antonio, TX) (no. 1134PC) and were conducted in Association for Assessment and Accreditation of Laboratory Animal Care-approved facilities.

Animal care and maintenance. Before pregnancy, maternal morphometric determinations were made to guarantee consistency of weight and general morphometrics in the female baboons used in the present study. Twelve nonpregnant female baboons (Papio species) of similar morphometric phenotype were selected for the study and randomly assigned to the control group or to a reduced maternal diet group. Animals were housed as previously described (55) at the Southwest National Primate Research Center at the Texas Biomedical Research Institute in Association for Assessment and Accrediton of Laboratory Animal Care-approved facilities.

Each outdoor concrete gang cage was covered with a roof and had open sides that allowed exposure to normal lighting. Each cage held $10-15$ female baboons and had a floor area of $37 \mathrm{~m}^{2}$, being $\sim 3.5 \mathrm{~m}$ high. The enrichment within the cages included nylon bones (Nylabone, Neptune, NJ), rubber Kong toys (Kong, Golden, CO), and plastic Jolly Balls (Horseman's Pride, Ravenna, OH). A 0.6-m-wide platform, built from expanded metal grating, was placed at a height of $1.7 \mathrm{~m}$ and ran the full length of the cage. A similar perch was built at the front of the cage, also running the length of the entire cage. Tube perches were present at the back in the corner of each cage. Each cage had an exit into a chute $0.6 \mathrm{~m}$ wide $\times 1 \mathrm{~m}$ high positioned along the side of each set of cages. A fine mesh was placed on the side of the chute adjacent to the other group cages between groups of animals as they passed along the chute to the individual feeding cages. The two chutes merged and passed over a scale and into individual feeding cages, which were $0.6 \times 0.9 \mathrm{~m}$ in floor area and $0.69 \mathrm{~m}$ high. All metal components were made of galvanized steel.

After the introduction of a fertile male, all female baboons were observed for determination of their reproductive cycle (turgescence of the sex skin) to determine the timing of pregnancy. On day 30 of pregnancy (term: $\sim 183$ days gestation), female baboons were randomly assigned to eat normal primate chow ad libitum (Purina Monkey Diet 5038, Purina, St. Louis, MO; control diet) or to receive $70 \%$ of the feed eaten by control female baboons (MNR group) on a body weight-adjusted basis ( $n=6$ baboons/dietary group). Water was given ad libitum. Animals remained in these groups until cesarean section at 165 days gestation ( 0.9 gestation). Specific details on the food composition have been previously published (55).

Cesarean section, fetal and maternal morphometry, and blood sampling. Cesarean sections were performed at 165 days gestation (0.9 gestation) under premedication with ketamine hydrochloride (10 $\mathrm{mg} / \mathrm{kg}$ ) followed by isoflurane anesthesia $(2 \%, 2 \mathrm{l} / \mathrm{min})$ to collect fetal samples and the placenta ( 3 control male fetuses, 3 control female fetuses; 3 MNR male fetuses, and 3 MNR female fetuses).

Before the fetus was exteriorized from the uterine cavity, umbilical vein blood sampling was performed as previously described (55). The fetus was euthanized by exsanguination while still under general anesthesia. The placenta and fetus were analyzed for morphometric measurements, complete pathological evaluation, and tissue sampling.
Fetal kidneys were rapidly removed and cut in half longitudinally. One half was immediately snap frozen in liquid nitrogen and then stored at $-80^{\circ} \mathrm{C}$ until used for RNA and protein extractions. The other half of the kidney was fixed in $10 \%$ buffered formalin and embedded in paraffin for histological analyses.

The techniques used and postoperative maintenance of the mother have been previously described in detail (56). All mothers were returned to their cages after recovery from cesarean section.

Biochemical analyses. Within $1 \mathrm{~h}$ of collection, clotted blood was centrifuged and the serum was removed. Biochemical determinations for glucose, blood urea nitrogen (BUN), creatinine, total protein, albumin, and globulin were made in serum using a Beckman Synchron CX5CE Analyzer (Beckman Coulter).

$R N A$ extraction. Total RNA extraction was performed in accordance with the protocol previously described by Cox et al. (11). RNA was quantified spectrophotometrically using a Thermo Scientific NanoDrop 2000 spectrophotometer (Thermo Scientific) and stored at $-80^{\circ} \mathrm{C}$. RNA purity and quality were checked by ultraviolet spectrophotometry by the ratios of 260-to-280-nm absorbance and 260-to230-nm absorbance and electrophoretically for visualization of ribosomal band integrity for both $18 \mathrm{~S}$ and $28 \mathrm{~S}$ rRNA. Only RNA samples that demonstrated consistent quality were used for later analysis.

cDNA preparation. After RNA preparation, samples were treated with DNase to ensure the elimination of genomic DNA, and extracted RNA was converted to cDNA using the $\mathrm{RT}^{2}$ First Strand Kit from SuperArray Bioscience (SA Biosciences) according to the manufacturer's instructions. The cDNA mixture was stored at $-20^{\circ} \mathrm{C}$ until used for gene expression profiling.

Quantitative gene expression profiling. The $\mathrm{RT}^{2}$ Profiler PCR Array System (SuperArray Bioscience) was used to evaluate the different renal mitochondrial transcripts between control and MNR fetuses. We used the Human Mitochondrial Energy Metabolism and Human Mitochondria PCR Pathway Arrays. Real-time PCR detection was carried out per the manufacturer's instructions. Data were normalized with three endogenous controls that did not differ between groups [hypoxanthine phosphoribosyltransferase 1 (HPRT1), ribosomal protein L13a $(R P L 13 A)$, and $\beta$-actin $(A C T B)]$ and analyzed with the $\Delta \Delta \mathrm{C}_{\mathrm{t}}$ method (where $\mathrm{C}_{\mathrm{t}}$ is threshold cycle) using the PCR Array Data Analysis Web Portal (SA Biosciences).

Tissue immunohistochemistry. Tissue immunohistochemistry was performed by a standard avidin-biotin histochemical technique as previously described (32). Initial titrations were performed with three different concentrations of primary antibody that contained the suggested dilution of the manufacturer. The final primary antibody concentration was adjusted to give the cleanest immunostaining achievable. Once the final dilution of the primary antibody was determined, all sections to be analyzed were immunostained in the same assay to assure identical conditions. Sections were covered with primary antibody overnight at $4^{\circ} \mathrm{C}$ [cytochrome $c$ oxidase $(\mathrm{COX})$ subunit VIc: mouse monoclonal antibody (sc-65240), mitofusin 2 (Mfn2): mouse monoclonal antibody (sc-100560), and translocase of inner mitochondrial membrane 9 (Tim9A): mouse monoclonal antibody (sc-101285) from Santa Cruz Biotechnology (Dallas, TX); and anti-cytochrome $c$ isoform 1 (CYC1): rabbit polyclonal antibody (HPA001247) from Sigma-Aldrich (St. Louis, MO)] and incubated for $1 \mathrm{~h}$ at room temperature with the secondary antibody. All biotinylated secondary antibodies were obtained from Vector Laboratories (Burlingame, CA): goat anti-rabbit (BA-1000) and horse antimouse (BA-2000). All were used at a 1:1,000 dilution. The appropriate negative controls were also run in the absence of the primary antibody but in the presence of normal serum. Three slides per animal were analyzed, and 6 pictures/slide per kidney section (cortex and medulla) were randomly taken and analyzed with ImageJ software (National Institutes of Health) for fraction (area immunostained/area of the field of interest $\times 100 \%)$ and density (in arbitrary density units). 
Data analysis and statistics. Data are expressed as means \pm SE. A nonparametric Mann-Whitney $U$-test was used. PCR array data were analyzed using the $\Delta \Delta \mathrm{C}_{\mathrm{t}}$ method and the web tools of SA Biosciences (http://www.sabiosciences.com/pcr/arrayanalysis.php). Statistical analyses were performed using SPSS (version 17.0) with significance set at $P<0.05$.

\section{RESULTS}

Biological changes resulting from MNR. Control and MNR groups did not differ in maternal body weight before pregnancy. However, at 0.9 gestation, ad libitum-fed control moth- ers weighed more than MNR mothers. The maternal control group gained $11.30 \pm 3.05 \%$ of their body weight during pregnancy. In contrast, MNR mothers significantly lost weight $(5.63 \pm 3.89 \%)$. Maternal weight loss was more pronounced in MNR mothers carrying male fetuses $(-10.51 \pm 5.41 \%$ vs. $-0.76 \pm 4.78 \%)$. Placental weight was also significantly decreased in MNR mothers $(-19.55 \pm 5.13 \%$; Table 1$)$.

At cesarean section, measurements of biomarkers for maternal renal function, such as BUN, creatinine, BUN creatine ratio, $\mathrm{Na}^{+}, \mathrm{K}^{+}$, and $\mathrm{CO}_{2}$, were not altered by $\mathrm{MNR}$, and only serum $\mathrm{Cl}^{-}$content was significantly decreased in MNR moth-

Table 1. Maternal and fetal morphological and biochemical parameters at 0.9 gestation in control ad libitum-fed pregnancies and in the presence of MNR to $70 \%$ of the food eaten by control mothers on a weight-adjusted basis

\begin{tabular}{|c|c|c|c|c|c|c|c|c|c|c|c|}
\hline & \multicolumn{2}{|c|}{ Sexes combined } & \multicolumn{2}{|c|}{ Male } & \multicolumn{2}{|c|}{ Female } & \multicolumn{5}{|c|}{$P$ Value (by Mann-Whitney $U$-Test) } \\
\hline & Control & MNR & Control & MNR & Control & MNR & Diet & $\begin{array}{c}\text { Control } \\
\text { male } \\
\text { versus } \\
\text { MNR male }\end{array}$ & $\begin{array}{l}\text { Control } \\
\text { female } \\
\text { versus MNR } \\
\text { female }\end{array}$ & $\begin{array}{l}\text { Control } \\
\text { male } \\
\text { versus } \\
\text { female }\end{array}$ & $\begin{array}{c}\text { MNR } \\
\text { male } \\
\text { versus } \\
\text { female }\end{array}$ \\
\hline $\begin{array}{l}\text { Number of } \\
\text { animals/group }\end{array}$ & 6 & 6 & 3 & 3 & 3 & 3 & & & & & \\
\hline \multicolumn{12}{|c|}{ Maternal characterization } \\
\hline $\begin{array}{l}\text { Weight preconception, } \\
\mathrm{kg}\end{array}$ & $15.18 \pm 0.95$ & $14.93 \pm 0.39$ & $13.67 \pm 0.61$ & $15.14 \pm 0.42$ & $16.69 \pm 1.36$ & $14.72 \pm 0.74$ & & & & & \\
\hline $\begin{array}{l}\text { Weight at cesarean } \\
\text { section, } \mathrm{kg}\end{array}$ & $16.80 \pm 0.79$ & $14.11 \pm 0.77$ & $15.91 \pm 0.98$ & $13.59 \pm 1.19$ & $17.70 \pm 1.17$ & $14.63 \pm 1.12$ & 0.037 & & & & \\
\hline Weight variation, $\%$ & $11.30 \pm 3.05$ & $-5.63 \pm 3.89$ & $16.27 \pm 4.26$ & $-10.51 \pm 5.41$ & $6.32 \pm 1.87$ & $-0.76 \pm 0.47$ & 0.01 & 0.05 & & 0.05 & \\
\hline Placental weight, $g$ & $181.67 \pm 7.77$ & $145.00 \pm 7.23$ & $180.33 \pm 10.33$ & $147.67 \pm 14.86$ & $183.00 \pm 13.89$ & $142.33 \pm 5.78$ & 0.01 & 0.05 & 0.05 & & \\
\hline \multicolumn{12}{|l|}{$\begin{array}{l}\text { Blood serum at } \\
\text { cesarean section }\end{array}$} \\
\hline BUN, mg/dl & $8.83 \pm 0.60$ & $9.33 \pm 1.02$ & $8.00 \pm 0.58$ & $7.67 \pm 0.33$ & $9.67 \pm 0.88$ & $11.00 \pm 1.53$ & & & & & \\
\hline Creatinine, mg/dl & $0.87 \pm 0.05$ & $1.02 \pm 0.10$ & $0.83 \pm 0.09$ & $0.93 \pm 0.07$ & $0.90 \pm 0.06$ & $1.10 \pm 0.21$ & & & & & \\
\hline BUN/creatinine & $10.31 \pm 0.80$ & $9.55 \pm 1.41$ & $9.72 \pm 0.84$ & $8.33 \pm 0.88$ & $10.90 \pm 1.45$ & $10.77 \pm 2.77$ & & & & & \\
\hline $\mathrm{Na}^{+}$, meq/l & $140.67 \pm 0.88$ & $140.50 \pm 1.09$ & $140.33 \pm 1.67$ & $142.00 \pm 1.15$ & $141.00 \pm 1.00$ & $139.00 \pm 1.53$ & & & & & \\
\hline $\mathrm{K}^{+}, \mathrm{meq} / \mathrm{l}$ & $3.60 \pm 0.12$ & $3.65 \pm 0.15$ & $3.77 \pm 0.18$ & $3.70 \pm 0.10$ & $3.43 \pm 0.12$ & $3.60 \pm 0.32$ & & & & & \\
\hline $\mathrm{Cl}^{-}$, meq/1 & $111.83 \pm 0.79$ & $109.50 \pm 1.41$ & $112.33 \pm 1.67$ & $111.00 \pm 2.52$ & $111.33 \pm 0.33$ & $108.00 \pm 1.15$ & & & 0.046 & & \\
\hline $\mathrm{CO}_{2}, \mathrm{meq} / \mathrm{l}$ & $22.00 \pm 0.86$ & $21.17 \pm 1.08$ & $23.00 \pm 0.58$ & $22.33 \pm 0.67$ & $21.00 \pm 1.53$ & $20.00 \pm 2.00$ & & & & & \\
\hline Anion gap, meq/l & $10.43 \pm 1.27$ & $13.48 \pm 1.49$ & $8.77 \pm 0.41$ & $12.37 \pm 2.24$ & $12.10 \pm 2.25$ & $14.60 \pm 2.21$ & & & & & \\
\hline $\mathrm{Ca}^{2+}, \mathrm{mg} / \mathrm{dl}$ & $8.46 \pm 0.11$ & $8.40 \pm 0.13$ & $8.43 \pm 0.19$ & $8.23 \pm 0.03$ & $8.50 \pm 0.10$ & $8.65 \pm 0.25$ & & & & & \\
\hline Phosphorus, mg/dl & $3.34 \pm 0.08$ & $3.22 \pm 0.13$ & $3.33 \pm 0.12$ & $3.33 \pm 0.18$ & $3.35 \pm 0.15$ & $3.05 \pm 0.15$ & & & & & \\
\hline Albumin, g/dl & $2.75 \pm 0.15$ & $2.72 \pm 0.05$ & $2.87 \pm 0.03$ & $2.73 \pm 0.07$ & $2.63 \pm 0.32$ & $2.70 \pm 0.10$ & & & & & \\
\hline Total protein, g/dl & $6.35 \pm 0.24$ & $6.28 \pm 0.20$ & $6.43 \pm 0.07$ & $6.00 \pm 0.25$ & $6.27 \pm 0.53$ & $6.57 \pm 0.24$ & & & & & \\
\hline $\begin{array}{l}\text { Total bilirubin, } \\
\mathrm{mg} / \mathrm{dl}\end{array}$ & $0.28 \pm 0.06$ & $0.32 \pm 0.06$ & $0.30 \pm 0.10$ & $0.30 \pm 0.06$ & $0.25 \pm 0.05$ & $0.35 \pm 0.15$ & & & & & \\
\hline $\begin{array}{l}\text { Alkaline } \\
\text { phosphatase, U/1 }\end{array}$ & $137.50 \pm 28.62$ & $178.67 \pm 43.49$ & $171.33 \pm 53.35$ & $163.33 \pm 13.93$ & $103.67 \pm 10.27$ & $194.00 \pm 95.02$ & & & & & \\
\hline $\begin{array}{l}\text { Alanine } \\
\text { aminotransferase, } \\
\mathrm{U} / 1\end{array}$ & $38.17 \pm 6.94$ & $58.50 \pm 12.53$ & $36.00 \pm 10.02$ & $53.33 \pm 13.98$ & $40.33 \pm 11.67$ & $63.67 \pm 23.73$ & & & & & \\
\hline $\begin{array}{l}\text { Aspartate } \\
\text { aminotransferase, } \\
\text { U/l }\end{array}$ & $22.17 \pm 2.63$ & $37.33 \pm 6.98$ & $22.00 \pm 2.65$ & $38.67 \pm 11.79$ & $22.33 \pm 5.24$ & $36.00 \pm 10.15$ & & & & & \\
\hline $\begin{array}{l}\gamma \text {-Glutamyl } \\
\text { transferase, U/1 }\end{array}$ & $31.60 \pm 1.69$ & $32.40 \pm 1.03$ & $31.00 \pm 2.65$ & $32.67 \pm 1.76$ & $32.50 \pm 2.50$ & $32.00 \pm 1.00$ & & & & & \\
\hline Cholesterol, mg/dl & $60.17 \pm 7.02$ & $64.17 \pm 7.53$ & $62.33 \pm 14.31$ & $57.33 \pm 8.21$ & $58.00 \pm 6.08$ & $71.00 \pm 13.00$ & & & & & \\
\hline Triglycerides, mg/dl & $29.40 \pm 3.91$ & $51.80 \pm 6.96$ & $29.33 \pm 5.67$ & $52.67 \pm 8.35$ & $29.50 \pm 7.50$ & $50.50 \pm 16.50$ & & & & & \\
\hline $\begin{array}{l}\text { Lactate } \\
\text { dehydrogenase, } \\
\text { U/1 }\end{array}$ & $190.40 \pm 17.54$ & $191.00 \pm 15.88$ & $167.33 \pm 15.50$ & $197.33 \pm 28.09$ & $225.00 \pm 19.00$ & $181.50 \pm 2.50$ & & & & & \\
\hline $\begin{array}{l}\text { Creatine } \\
\text { phosphokinase, } \\
\text { U/1 }\end{array}$ & $291.00 \pm 62.75$ & $357.40 \pm 128.24$ & $376.67 \pm 60.98$ & $390.67 \pm 230.36$ & $162.50 \pm 26.50$ & $307.50 \pm 33.50$ & & & & & \\
\hline \multicolumn{12}{|c|}{ Fetal characterization } \\
\hline Weight, g & $755.00 \pm 35.22$ & $668.50 \pm 33.41$ & $784.33 \pm 46.16$ & $711.00 \pm 55.19$ & $725.67 \pm 56.68$ & $626.00 \pm 27.01$ & & & & & \\
\hline Body length, cm & $36.42 \pm 0.90$ & $37.50 \pm 1.02$ & $37.33 \pm 0.44$ & $38.50 \pm 1.26$ & $35.50 \pm 1.73$ & $36.50 \pm 1.61$ & & & & & \\
\hline Femur length, $\mathrm{cm}$ & $7.71 \pm 0.28$ & $7.25 \pm 0.21$ & $7.33 \pm 0.17$ & $7.67 \pm 0.17$ & $8.08 \pm 0.46$ & $6.83 \pm 0.17$ & & & 0.046 & & 0.043 \\
\hline $\begin{array}{l}\text { Body mass index, } \\
\mathrm{kg} / \mathrm{m}^{2}\end{array}$ & $5.70 \pm 0.22$ & $4.77 \pm 0.20$ & $5.65 \pm 0.45$ & $4.78 \pm 0.15$ & $5.76 \pm 0.19$ & $4.75 \pm 0.42$ & 0.025 & & 0.05 & & \\
\hline Kidney weight, g & $3.54 \pm 0.26$ & $3.56 \pm 0.27$ & $3.78 \pm 0.52$ & $3.60 \pm 0.17$ & $3.30 \pm 0.08$ & $3.51 \pm 0.59$ & & & & & \\
\hline $\begin{array}{c}\text { Kidney weight/body } \\
\text { weight, } \times 1,000\end{array}$ & $4.71 \pm 0.31$ & $5.39 \pm 0.53$ & $4.80 \pm 0.54$ & $5.10 \pm 0.33$ & $4.62 \pm 0.44$ & $5.68 \pm 1.11$ & & & & & \\
\hline Brain weight, $\mathrm{g}$ & $77.30 \pm 3.63$ & $77.69 \pm 2.49$ & $82.27 \pm 4.45$ & $77.59 \pm 4.90$ & $72.33 \pm 4.63$ & $77.79 \pm 2.62$ & & & & & \\
\hline $\begin{array}{r}\text { Brain weight/body } \\
\text { weight, } \times 1,000\end{array}$ & $103.00 \pm 5.45$ & $116.92 \pm 3.86$ & $106.13 \pm 11.44$ & $109.39 \pm 1.94$ & $99.93 \pm 2.84$ & $124.46 \pm 3.71$ & 0.037 & & & & 0.05 \\
\hline
\end{tabular}

Data are means \pm SE. MNR, maternal nutrient reduction; BUN, blood urea nitrogen. 
ers carrying female fetuses. A statistical tendency was found for a diet effect on serum triglycerides $(P=0.056)$, namely for MNR mothers carrying male fetuses. In this group, an increase of $79 \%$ of circulating blood serum triglycerides was observed compared with mothers that received the control diet and carrying a male fetus. In terms of fetal morphometrics, MNR decreased the fetal body mass index by $16.7 \%(P=0.02)$. In addition, femoral length from MNR female fetuses was decreased compared with the control group $(P=0.046)$. However, MNR did not alter fetal kidney weight or the kidney weight-to-body weight ratio, although the brain weight-tobody weight ratio increased significantly in MNR fetuses.

Fetal and maternal cortisol, glucose, and insulin levels. Circulating cortisol in ad libitum-fed control mothers was $\sim 2.7$-fold higher than in their offspring at 0.9 gestation (Fig. 1). A proportional increase in cortisol was observed in both maternal and fetal blood serum in MNR baboons. However, this increase only reached statistical significance in MNR mothers carrying male fetuses and in the serum of MNR fetuses, namely due to effects on MNF female fetuses. The results also show an analogous maternal-to-fetal circulating cortisol gradient in control and MNR pregnancies (Fig. 1A). The maternal-to-fetal cortisol gradient was not different in MNR compared with control pregnancies.

Plasma glucose in control mothers fed ad libitum was 1.8 -fold higher than that of their fetuses at 0.9 gestation $(P<0.05)$. However, no difference was observed in glucose levels between control and MNR fetuses when sexes were either combined or separated (Fig. 1B). Only MNR mothers carrying male fetuses registered a significant increase in glucose levels. There was a trend for increased maternal insulin levels in all MNR mothers; however, due to variability in the data obtained, the difference did not reach significance. Insulin levels in control mothers were 4.1 -fold greater than in fetuses ( 0.9 gestation). Diet effects were observed only in fetal male insulin levels (Fig. 1C).

MNR affects key mitochondrial genes in the fetus kidney. The Human Mitochondrial Energy Metabolism and Human Mitochondria Pathway Arrays were used for expression profiling in fetal kidney RNA samples. The complete set of data is
Fig. 1. Cortisol, glucose, and insulin levels in maternal and fetal plasma of control (C) and maternal nutrient reduction (MNR) groups. These parameters were determined in maternal and fetal plasma of control ad libitum-fed pregnancies and in the presence of MNR, characterized as $70 \%$ of the food consumed by control mothers on a weightadjusted basis of baboons at 0.9 gestation. $A$ : cortisol levels in maternal and fetal plasma of control and MNR baboons (male fetuses: $n=3$; female fetuses: $n=3$ ). C-M, male fetuses from the control group; C-F, female fetuses from the control group; MNR-M, male fetuses from the MNR group; MNR-F, female fetuses from the MNR group. $B$ : glucose levels in maternal and fetal plasma of control and MNR $(n=6)$ baboons (male fetuses: $n=3$; female fetuses: $n=3$ ). $C$ insulin levels in maternal and fetal plasma of control and MNR baboons (male fetuses: $n=3$; female fetuses: $n=3$ ). Values are means \pm SE; $n=3$ (when separated by sex) or 6 (sexes combined) animals/group. ${ }^{*} P<$ 0.05 vs. the respective controls.
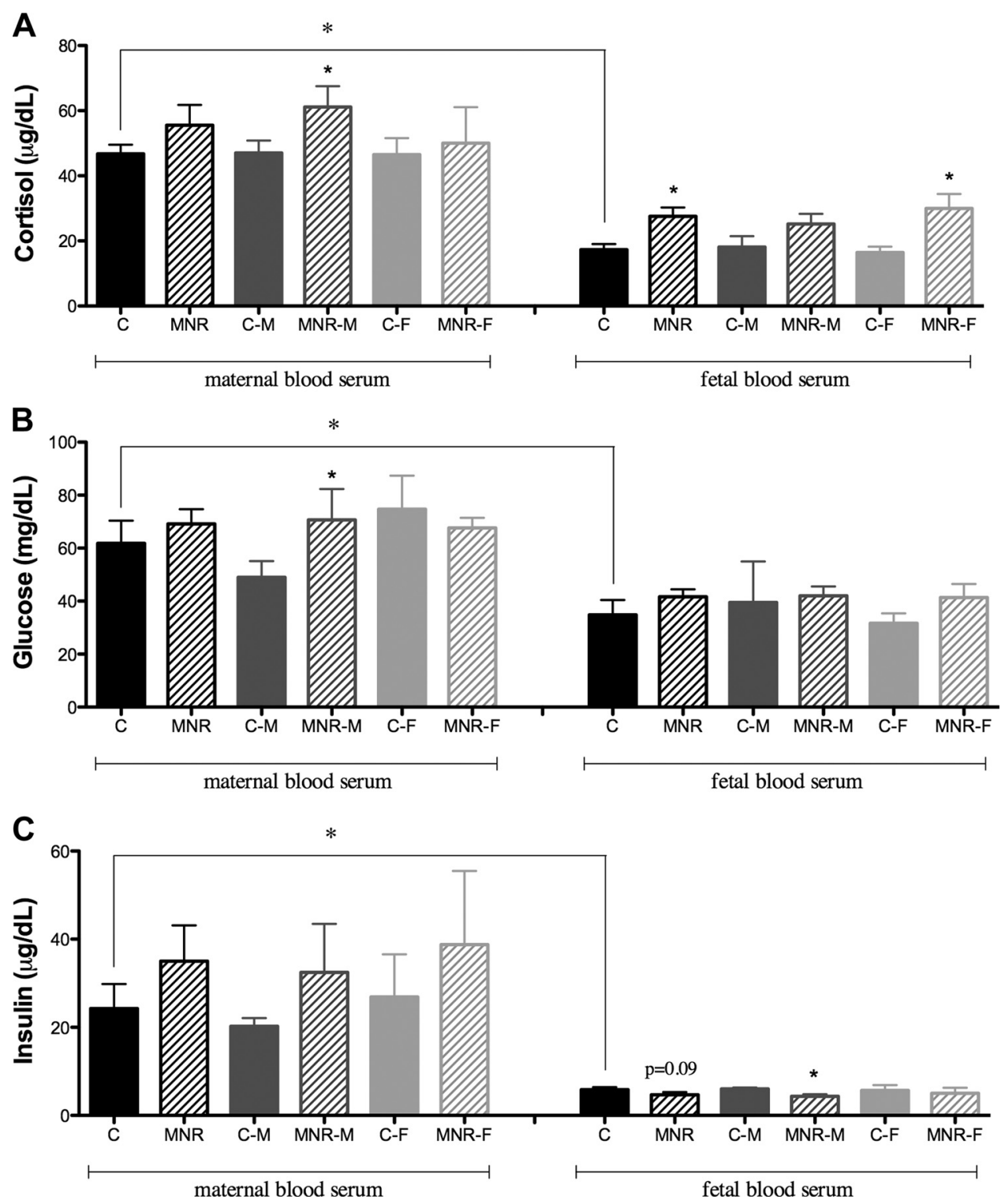
shown in Supplemental Table $\mathrm{S} 2^{1}$ and shown in Fig. 2. PCR arrays presented a residual percentage of absent calls $(7.5 \%$ and 3\% for the respectively array). The mitochondrial genes investigated showed diet-dependent effects, with a significant overall decreased expression of mitochondrial genes in MNR fetuses compared with control fetuses, with the greatest alterations occurring when sexes were combined (Fig. 2E). There were 46 genes differentially expressed in the MNR group, with $93 \%$ of the alterations involving downregulation. Most of the downregulated transcripts encoded subunits of mitochondrial OXPHOS, including 18 of 33 subunits analyzed from complex I: NADH dehydrogenase (ubiquinone) (NDUF)Al, NDUFA2, NDUFA4, NDUFA5, NDUFA7, NDUFA8, NDUFA10, NDUFA11, NDUFAB1, NDUFB5, NDUFB9, NDUFC1, NDUFC2, NDUFS3, NDUFS4, NDUFS5, NDUFS8, and NDUFV3; 2 of 4 subunits analyzed for complex II: succinate dehydrogenase $(S D H) A$ and $S D H B ; 2$ of 6 subunits analyzed for complex III: ubiquinol-cytochrome c reductase core protein 1 (UQCRC1) and ubiquinol-cytochrome c reductase, Rieske iron-sulfur polypeptide 1 (UQCRFSI); 4 of 14 subunits analyzed for complex IV: COX4I1, COX5A, COX5B, and COX8C; oxidase (cytochrome c) assembly 1-like $(O X A 1 L)$, an essential factor for the activity and assembly for this complex; and 8 of 21 subunits analyzed for ATP synthase: ATP4A, ATP4B, ATP5B, ATP5G1, ATP5J, ATP5O, ATP6V0A2, and ATP6VIC2. In addtion, transcripts for regulators and mediators of mitochondrial molecular transport, namely small-molecule transporters [solute carrier (SLC)25A15, SLC25A16, SLC25A23, $S L C 25 A 27$, and SLC25A31] and two members of the inner membrane translocation system [translocase of inner mitochondrial membrane (TIMM) 23 homolog (TIMM23) and fracture callus 1 homolog $(F X C 1)]$ were also downregulated in the MNR group. Finally, two members of the inorganic pyrophosphatase family, which catalyze the hydrolysis of pyrophosphate to inorganic phosphate [pyrophosphatase (inorganic) $(P P) A 1$ and PPA2] and ultimately mitochondrial apoptosisinducing factor 2 (AIFM2), which plays a role as a caspaseindependent apoptotic factor, were also downregulated.

A significant sexual dimorphism was shown in the mitochondrial profile of control fetuses. Females fetuses presented a higher content in transcripts for NDUFV1, a complex I subunit; COX6A1, a COX subunit; ATP5C1, an ATP synthase subunit; inner membrane peptidase-1 inner mitochondrial membrane peptidase-like (IMMPIL), a subunit of mitochondrial inner membrane peptidase; TIMM9, an inner mitochondrial membrane protein translocase; $B I D$, a member of the Bcl-2 family of cell death regulators; and stratifin $(S F N)$, a p53-regulated inhibitor of $\mathrm{G}_{2} / \mathrm{M}$ progression. On the other hand, female fetuses contained decreased abundance of transcripts for optic atrophy 1 (OPAl), which is required for mitochondrial fusion and regulation of apoptosis; SLC25A17, a peroxisomal transporter for multiple cofactors such as CoA, flavin adenine dinucleotide, flavin mononucleotide, and nucleotide AMP; TIMM17A, an essential component of the TIM23 complex, a complex that mediates the translocation of proteins across the mitochondrial inner membrane; translocase of outer mitochondrial membrane 70 homolog A (TOMM70A), which

\footnotetext{
${ }^{1}$ Supplemental Material for this article is available at the American Journal of Physiology-Renal Physiology website.
}

encodes a component of the outer membrane translocase complex, and SOD1, cytosolic SOD.

Diet-induced transcript differences were also observed within the same sex. In summary, multiple components of the mitochondrial respiratory chain were reduced in MNR male fetuses, including two subunits of complex I (NDUFAl and NDUFA4), one subunit of complex II (SDHB), and one ATP synthase subunit (ATP6V1C2). Decreased transcripts also included SOD1 as well as TIMM23, a gene encoding a component of the inner mitochondrial membrane import system. On the other hand, one complex IV subunit (COX6Al) was significantly increased (1.7-fold) as well as $S F N$, which has been implicated in the regulation of a large spectrum of both general and specialized signaling pathways. In MNR female fetuses, the same trend was found, although with a slight difference in the subunits affected by maternal diet. MNR resulted in a significant decrease in the abundance of transcripts for the mitochondrial respiratory chain, including NDUFS5 and NDUFV3, two subunits from complex I, COX6C and COX7B, two subunits from complex IV, as well as ATP synthase subunit F6 (ATP5J). Other significant diet-induced downregulated gene expression occurred for MFN2, which is involved in mitochondrial fusion; three solute mitochondrial carrier family 25 genes (SLC25A16, SLC25A17, and SLC25A31, an adenine nucleotide translocator), proapoptotic Bcl-2-binding component 3 (BBC3), BID, a mediator of mitochondrial damage induced by caspase-8, and STAR-related lipid transfer domain 3 (STARD3), which encodes for a lipid trafficking protein that may be involved in exporting cholesterol. The two transcripts that were significantly upregulated in MNR female fetuses were cyclin-dependent kinase inhibitor $2 \mathrm{~A}(C D K N 2 A)$, a stabilizer of the tumor suppressor protein p53, and one solute mitochondrial carrier family 25 gene (SLC25A15, coding for an ornithine transporter).

MNR offspring present altered mitochondrial protein content. The tissue content of four mitochondrial proteins (COX6C, CYC1, MFN2, and TIMM9A) was also measured by immunohistochemistry. Due to the structural and functional diversity of the kidney accompanied by a wide variation in the local presence of different mitochondrial enzymes, we decided to quantify mitochondrial proteins in two regions of the kidney, the cortex and medulla. In agreement with the observed decrease in mRNA expression of respiratory chain subunits, a decrease in COX6C, a subunit of complex IV, was measured in MNR male fetuses (Fig. 3). Under control diet conditions, control female fetuses had a 1.82 -fold decrease content of COX6C fraction stained (in \%) and a 1.14-fold decrease in density (in arbitrary units) in the renal cortex compared with control male fetal samples (for details, see Fig. 4). Notwithstanding, MNR female fetuses presented a significant increase in complex III subunit CYC1, detected by an increase of 1.37 -fold in the cortex fraction stained (in \%) and in density (in arbitrary units; Fig. 5).

There were no differences between diets or sexes in the quantitative immunohistochemistry of MNF2 or TIMM9A in the renal tissue analyzed (Fig. 6).

\section{DISCUSSION}

The baboon model in intrauterine programming studies. Several studies exist on developmental programming in altri- 
A

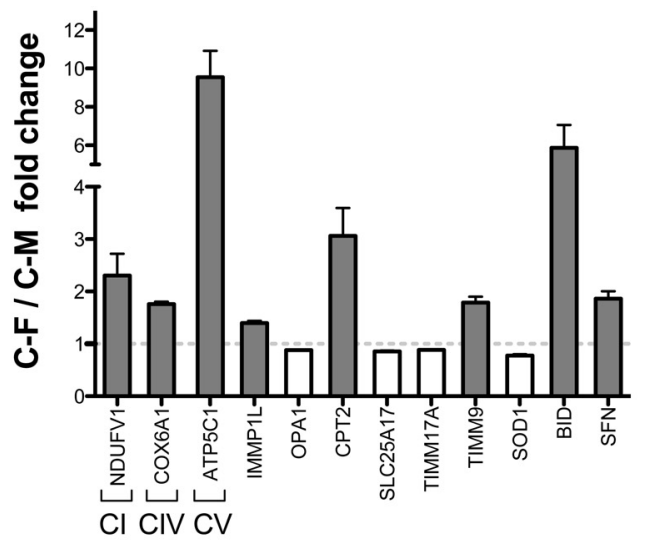

C

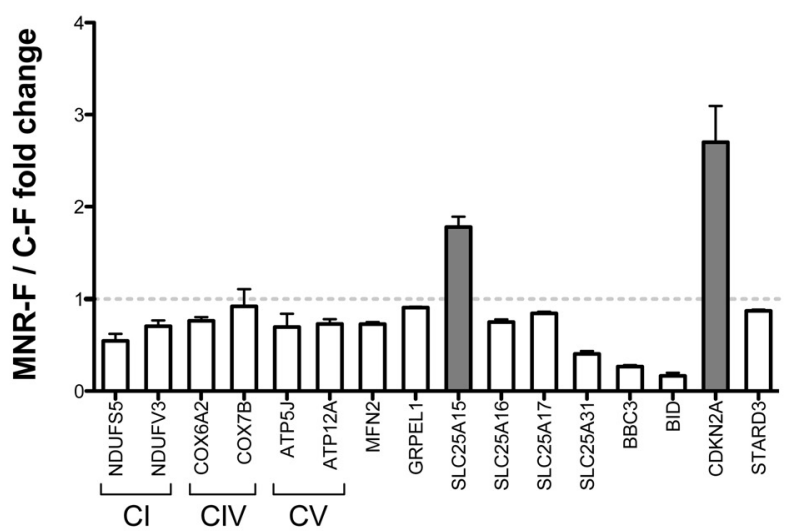

B

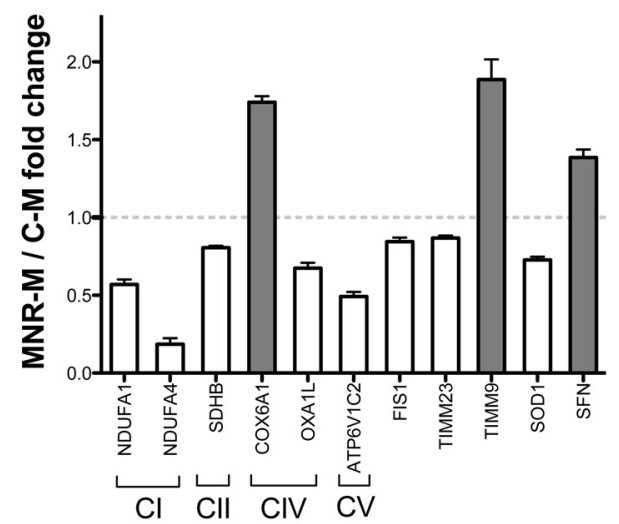

D

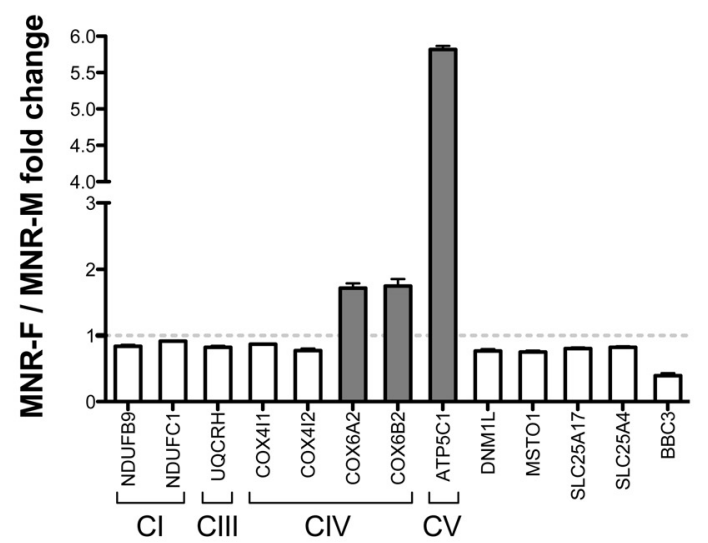

$\mathbf{E}$

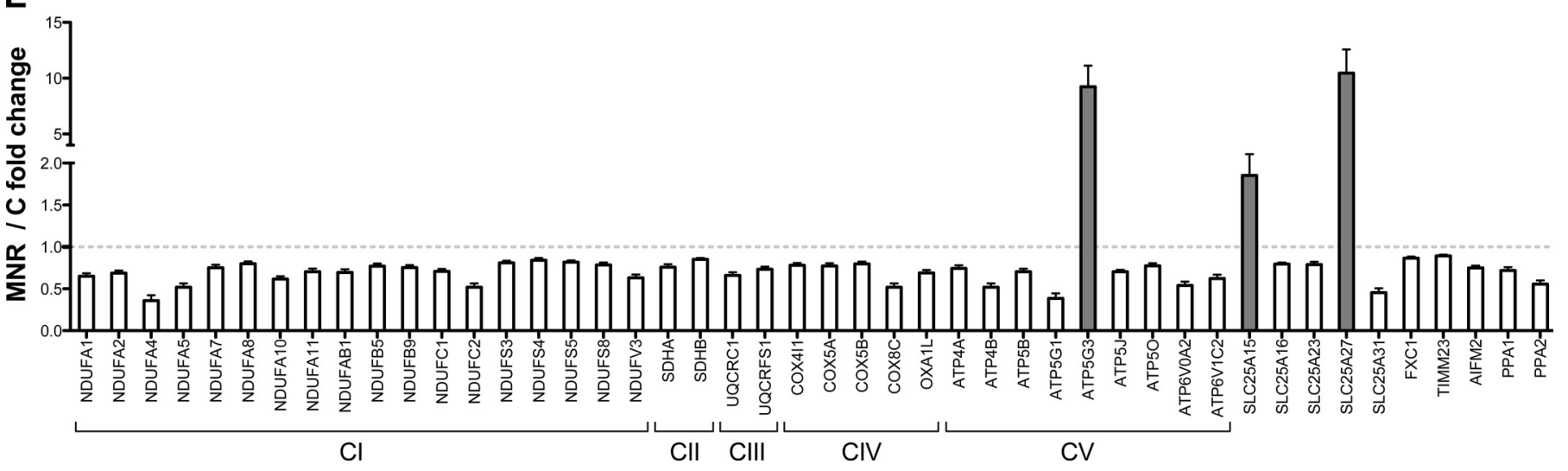

Fig. 2. Renal gene expression analysis of control and MNR baboon fetuses at 0.9 gestation. mRNA abundance for mitochondrial proteins was assessed by PCR array in whole kidney samples from baboon fetuses from mothers fed ad libitum (control group) or $70 \%$ of the control diet (MNR group) at 0.9 gestation. A: sexual dimorphism in the mitochondrial profile of control fetuses. $B$ : and $C$ : comparison of transcript expression based on maternal diet for the same sex [male fetuses $(B)$ and female fetuses $(C)]$. D: sexual dimorphism in the mitochondrial profile of MNR fetuses. $E$ : global diet-dependent effects in the mitochondrial expression profile. Transcripts related to oxidative phosphorylation system (OXPHOS), complex I (CI; NADH ubiquinone reductase), complex II (CII; succinate:ubiquinone reductase), complex III (CIII; ubiquinol:cytochrome $c$ reductase), complex IV [CIV; cytochrome $c$ oxidase (COX)], and complex V (CV; ATP synthase). Values were normalized to endogenous controls [hypoxanthine phosphoribosyltransferase 1 (HPRT1), ribosomal protein L13a (RPL13A), and $\beta$-actin $(A C T B)]$ and expressed relative to their normalized values. Values are means \pm SE; $n=3$ (when separated by sex) or 6 (sexes combined) animals/group. All transcripts presented have $P<0.05$ vs. the respective paired group. See the Supplemental Material and Table 1 for gene abbreviations used.

cial, polytocous rodent species $(3,7,17)$, but there are few in precocial, monotocous species $(11,45)$. Much of prenatal renal development in primates, including humans and baboons, occurs postnatally in rodents $(6,43)$. This difference is important because the intrauterine environment differs from the postnatal environment in many different ways, which can significantly affect that developmental trajectory of development. $\mathrm{O}_{2}$ tension and hence the potential for oxidative stress, metabolite concentrations, such as glucose, and of particular importance, fetal glucocorticoid levels, which rise prenatally in precocial 
species $(21,39)$ and postnatally in altricial species $(39)$, can be factors of segregation. Studies in nonhuman primates are important since they allow for a more direct translation to the human developmental programming. To our knowledge, the model we

A
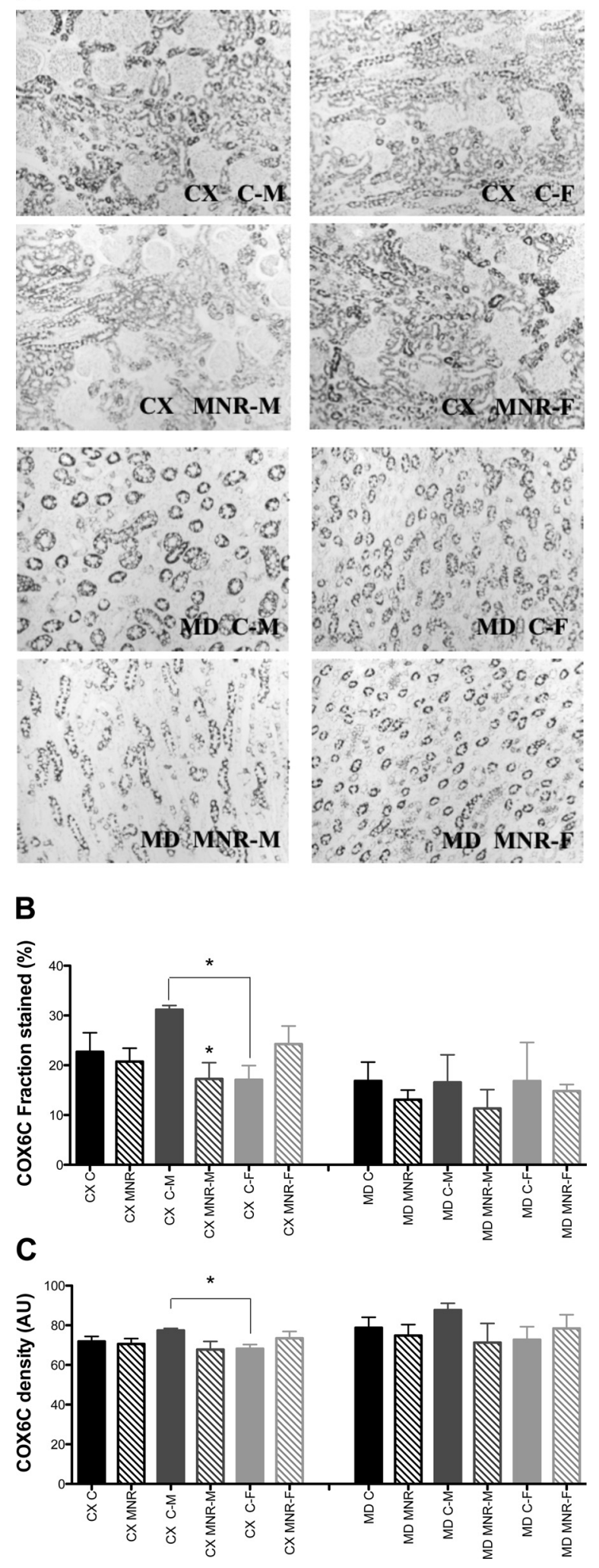
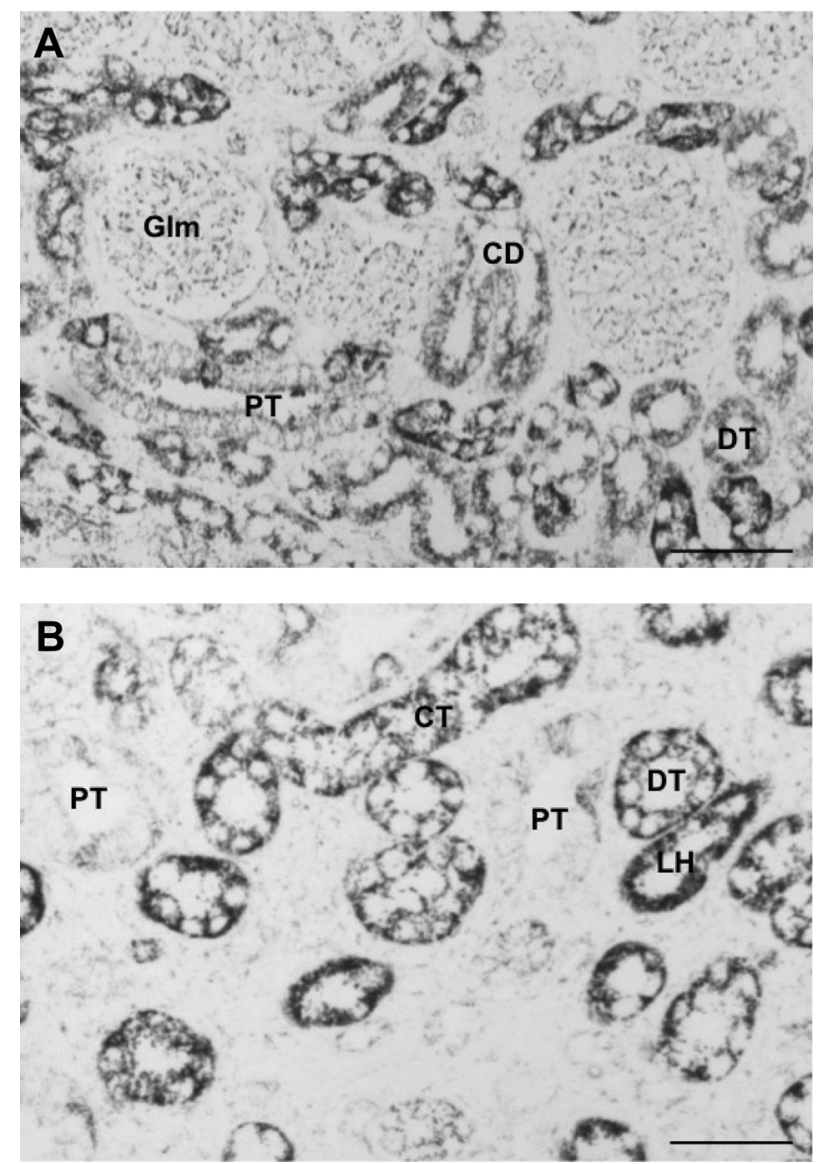

Fig. 4. Magnification of the immunohistochemistry images shown in Fig. $3 A$ [CX $(A) \mathrm{MD}(B)$ of a control male fetus]. A: immunolabeling for COX6C was associated with distal tubuli (DT), proximal tubuli (PT), collecting ducts (CD), and glomeruli $(\mathrm{Glm})$ in CX samples from a male fetal baboon from mothers that were fed ad libitum. $B$ : COX6C was associated with DT, CD, limbs of Henle's Loop (HL), and PT in MD samples from a control male kidney. However, immunolabeling for COX6C was more consistent in DT in the MD section. Scale bar $=50 \mu \mathrm{m}$.

present here is the first to test the concept of developmental programming as modified by reduced maternal nutrition. In our experimental animal model, a careful selection of mothers of similar phenotype before breeding was performed, which added power to the observations and were unable to be replicated in human studies.

Fetal baboon development closely resembles that of the human fetus, allowing targeted nutritional manipulations during specific periods of organogenesis. Most notably, development of the metanephros or "final" kidney occurs at a similar gestational time in humans and baboons. Kidney development in humans begins in the 9th week of gestation and ends around the 36th week of gestation (36). This corresponds to 0.9

Fig. 3. Quantitative immunohistochemistry of mitochondrial subunit COX6C in renal tissue of fetal baboons. The fetuses analyzed were from mothers that were fed ad libitum (control group) or $70 \%$ of the control diet (MNR group). $A$ : representative micrographs (magnification: $\times 20$ ) of cortex $(\mathrm{CX})$ and medulla (MD) sections of male and female fetuses. Immunoreactivity was expressed as fraction stained (in \%; $B$ ) and density $[C$; in arbitrary units (AU)]. Data are expressed as means \pm SE; $n=3$ (when separated by sex) or $n=6$ (sexes combined) animals/group. ${ }^{*} P<0.05$. 
gestation of the human fetus, exactly the same time point analyzed in our baboon model. The evolutionary similarity of mitochondrial genes between baboons and humans was also evident by the efficacy of human primers in baboon samples. In
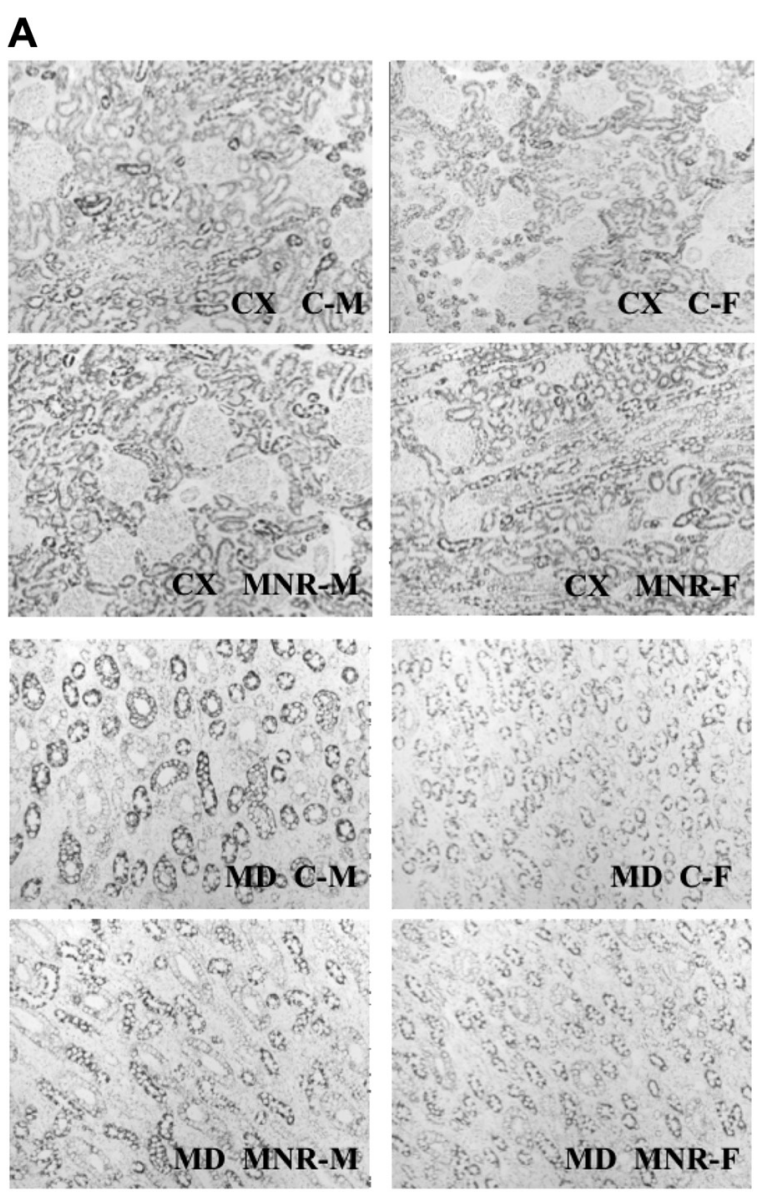

B

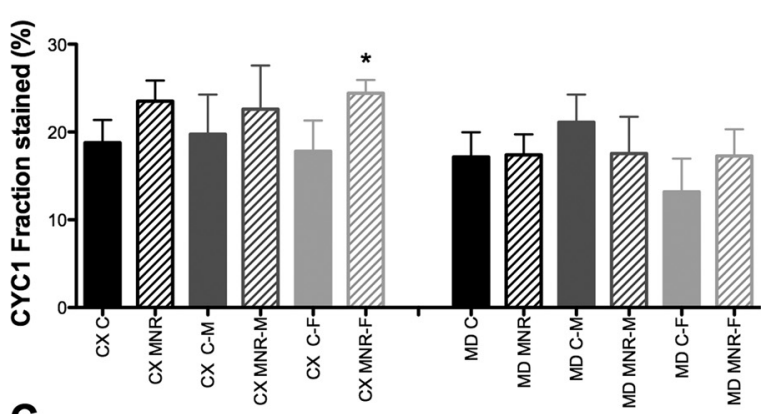

C

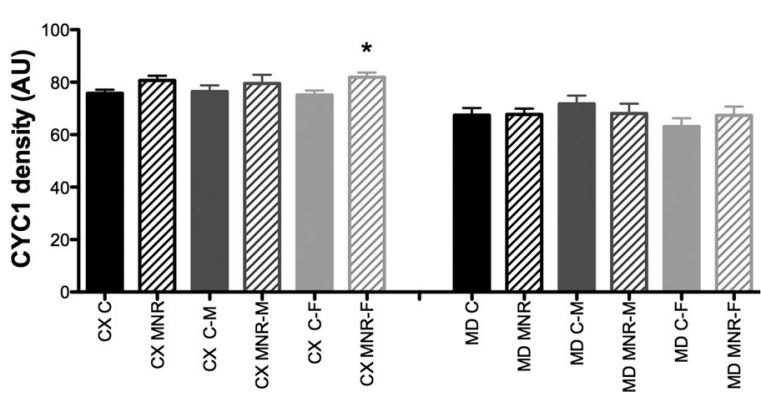

addition, baboons and humans share a broad range of physiological similarities that make baboons particularly valuable for analysis of gene-gene and gene-environment interactions (53) while both breeding and environmental factors can still be carefully controlled to suit experimental purposes. Furthermore, baboons develop spontaneous diabetes and diabetic nephropathy with morphological changes that resemble diabetic nephropathy found in humans (52). Diabetic baboons have larger glomeruli, increased glomerular and tubular basement membrane thicknesses, and matrix expansion with increased deposition of fibronectin and laminin, thus making this animal an attractive, although expensive, model for human diabetic nephropathy (52) or hypertension (61).

Intrauterine programming of adult life phenotype by maternal diet in the baboon. The majority of studies on developmental programming by maternal nutrition have been performed in rodents, and much less is known about the impact of nutrient reduction on fetal primate development. The strength and relevance of the baboon fetal experiments we have performed lie not only in its phylogenetic and developmental proximity to humans but also in the moderate level of MNR used, which produces a level of IUGR $(\sim 14 \%$ birth weight reduction) that is commonly seen in human pregnancy. We have previously demonstrated that consumption of $70 \%$ of a global ad libitum control diet by female baboons carefully selected to be of similar age and phenotype at conception resulted in impaired development of the fetal kidney $(11,44)$, brain (1), liver (32), and pancreatic islets (15). In addition, MNR during pregnancy and lactation programs offspring behavioral function (28) and metabolic responses, increasing insulin resistance and $\beta$-cell responsiveness, resulting in emergence of an overall phenotype that would predispose to later life type 2 diabetes (8). We hypothesize that permanent alterations in gene expression related to mitochondrial function and communication, set in motion by a suboptimal intrauterine environment, contribute to the development of cardiovascular or kidney diseases later in life. The present study is the first to demonstrate significant alterations in mitochondrial gene expression profile in fetal baboon kidneys challenged by MNR in utero.

Morphological and biochemical data. IUGR associated with MNR affects organ development. In fact, nephron numbers are lower in IUGR neonates. One hypothesis is that when challenged by limited resources, energy resource allocation is prioritized for brain, cardiac, and adrenal growth, whereas organs such as the kidneys and lungs receive lower priority (5). This allocation process is thought to be the root mechanism by which relative brain sparing and increased compromise in nonprotected organs takes place. A significant decrease in maternal weight gain during pregnancy was found for MNR mothers, which culminated in offspring with lower body mass

Fig. 5. Quantitative immunohistochemistry of mitochondrial subunit cytochrome $c$ isoform 1 (CYC1) in renal tissue of fetal baboons. The fetuses analyzed were from mothers that were fed ad libitum (control group) or $70 \%$ the control diet (MNR group). A: representative micrographs (magnification: $\times 20$ ) of CX and MD sections of male and female fetuses. Immunoreactivity was expressed as fraction stained $(B$; in $\%)$ and density $(C$; in AU). Data are expressed as means $\pm \mathrm{SE} ; n=3$ (when separated by sex) or 6 (sexes combined) animals/group. $* P<0.05$. 
A
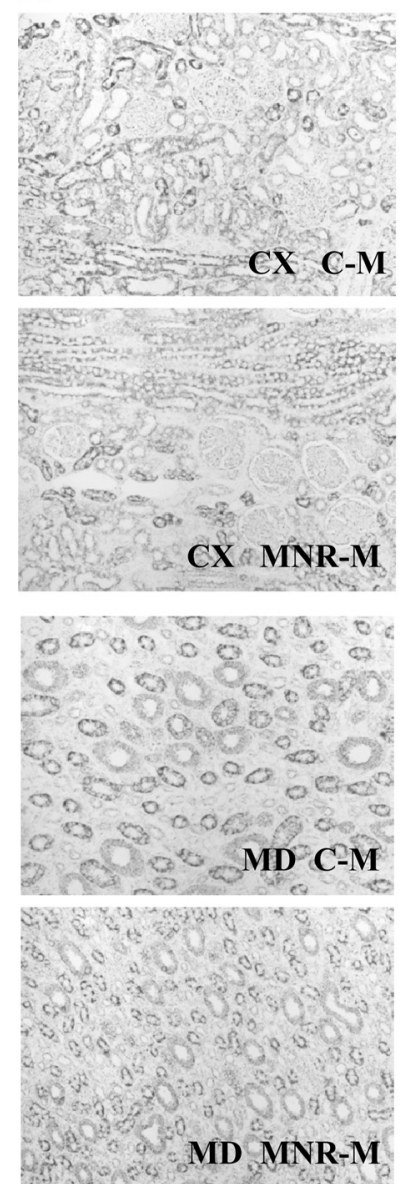

MFN2
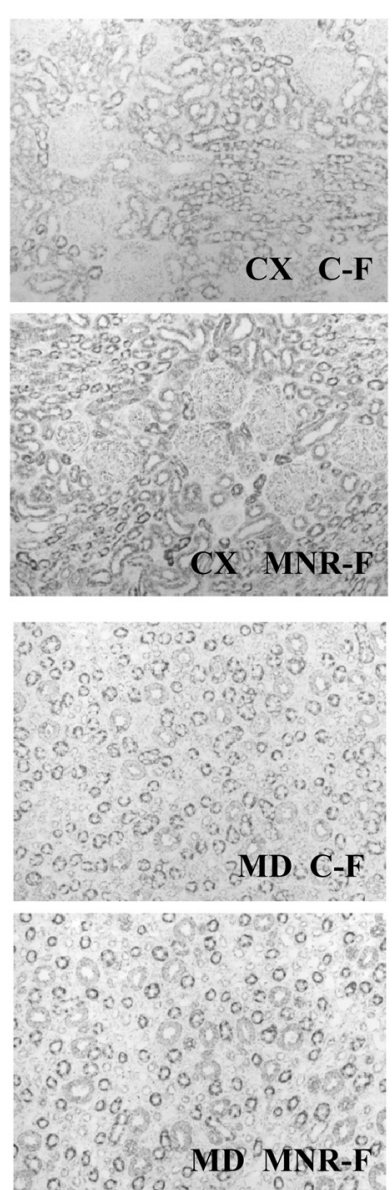

B
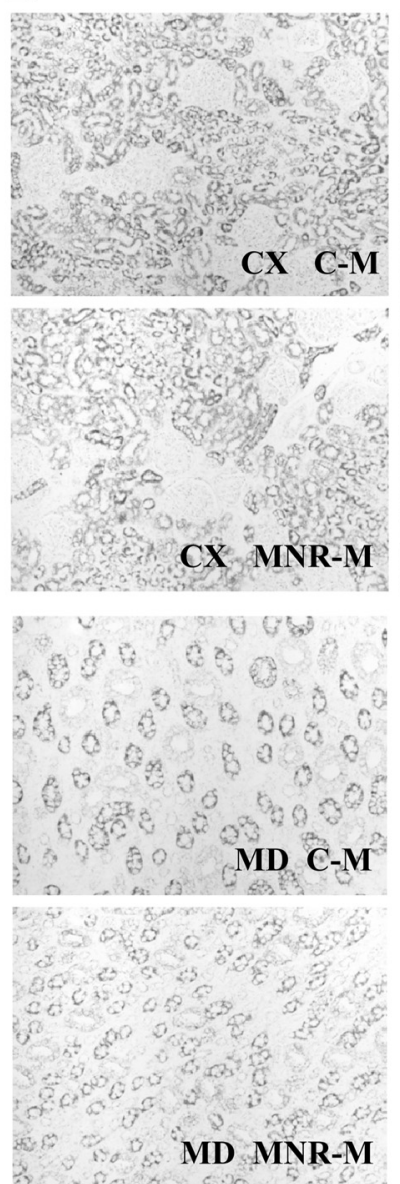

TIMM9A

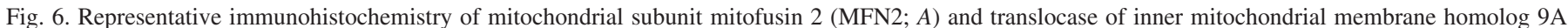

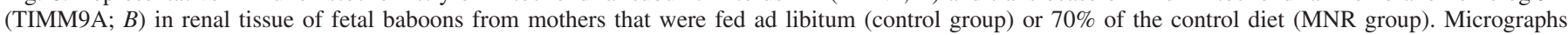
(magnification: $\times 20$ ) of $\mathrm{CX}$ and MD sections of male and female fetuses are shown.

indexes and with higher brain weight-to-body weight ratios. This diet effect was more visible for MNR female fetuses, with a significant decrease in femur length. However, MNR did not significantly affect kidney weight or the kidney weight-to-body weight ratio. These results indicate that the MNR protocol used in this work has a significant influence on body weight gain in the mother and influences fetal body mass index.

MNR significantly altered maternal and fetal endocrine factors, causing increased circulating cortisol and glucose in MNR mothers carrying male fetuses, significantly increasing circulating cortisol in the fetus independently of the fetal sex (Fig. 1). Maternal glucose metabolism was also impaired, since circulating glucose was significantly increased by MNR in mothers carrying male fetuses. Despite MNR promoting a decrease in fetal insulin in male fetuses, these changes did not appear to impact overall fetal glucose levels, since circulating fetal glucose was not significantly affected by MNR.

Increased circulating cortisol resulting from MNR is nonetheless important. Exposure of the fetus to glucocorticoid levels higher than required for the current stage of maturation triggers the expression of glucocorticoid target genes involved in energy metabolism and adipocyte differentiation, having been linked to the development of hyperglycemia, insulin resistance, and obesity later in life (13). Glucocorticoid-induced gene demethylation likely also contributes to the "memory" of the developmental nutritional challenge (63).

Concerning markers of renal and hepatic functions, no significant alteration in serum alanine aminotransferase or in BUN or BUN/creatinine levels were found, suggesting no alterations in that metabolic pathway. In general, the lack of difference in total protein between control and MNR mothers may imply that MNR mothers manage to successfully maintain amino acid levels. Since the reduction in total caloric intake by MNR mothers was moderate compared with the control diet, we cannot eliminate the possibility that MNR mothers blunted the decrease in fetal nutrient availability through utilization of endogenous stores.

Mitochondrial transcripts are decreased in MNR fetuses. A modified embryonic-fetal developmental trajectory resulting in low birth weight has been associated with reduced nephron endowment, hypertension, and renal diseases in adulthood (36, $37,47)$. Several molecular mechanisms have been suggested as contributing to impaired nephrogenesis (9); however, little attention has been given to the involvement of mitochondria as mediators linking fetal MNR with later lifetime consequences. 
The postnatal switch from glycolytic to oxidative metabolism is of crucial importance for all mammalian neonates and is essential for successful adaptation to extrauterine life (20). After birth, $>90 \%$ of ATP is produced by mitochondrial ATP synthase, which uses energy of the proton electrochemical gradient generated by respiratory chain complexes during substrate oxidation. The cellular capacity for energy provision relies on adequate biosynthesis of respiratory chain complexes and their proper assembly in the inner mitochondrial membrane. This process is under direct influence of numerous genes in nuclear and mitochondrial DNA (12).

Alterations of mitochondrial gene expression are likely important determinants for the development and function of major organ systems as well for susceptibility to disease.

A recent study from Fedovora et al. (18) using a model of chronic renal failure in male Sprague-Dawley rats observed mitochondrial impairments involving a 30\% decrease in mitochondrial DNA copy number and an $\sim 50 \%$ decrease in inner mitochondrial membrane proteins.

In a previous work (10), we found decreased tubule size in IUGR baboon fetal kidneys at 0.5 gestation, suggesting that IUGR alters kidney developmental trajectory. We also found that mammalian target of rapamycin signaling, a key nutrient sensing pathway, was inhibited in IUGR 0.5 gestation fetal kidneys compared with control kidneys. These findings suggest that mammalian target of rapamycin signaling via nutrient status influences tubule size (45). Because alterations of mitochondrial function are important determinants of development and function for major organ systems, we investigated the role of mitochondrially related genes and proteins in the near-term baboon fetal kidney, i.e., are the effects of MNR observed at 0.5 gestation persistent at 0.9 gestation, and, if so, what are the potential underlying mechanisms?

In accordance, our transcriptomic analysis showed significant alterations in mitochondrially relevant transcripts in the MNR fetal kidney. A large number of transcripts encoding subunits of the respiratory chain, ATP synthase, and cytochrome $c$ and other regulators and mediators of mitochondrial metabolite transport were found to be decreased by MNR. When examined using immunohistochemistry, changes were observed in the protein abundance of $\mathrm{COX} 6 \mathrm{C}$, a COX subunit. Differences in gene expression do not always lead to altered protein and enzyme activity, and, as in our findings, protein and mRNA measurements are not always in agreement. However, these findings, when taken together, suggest that MNR kidney mitochondrial alterations can potentially significantly affect the renal energy balance and act as a primer for later disease during adulthood. The changes likely account, at least in part, for an impairment of mitochondrial function and ATP production in MNR fetuses. The passage from a predominantly in utero anaerobic to postbirth aerobic metabolism can potentially exacerbate the observed effects of altered expression of mitochondrial genes. This should be confirmed in the future using freshly obtained samples containing functional mitochondria. Moreover, sex differences are apparent early in fetal development, suggesting that innate mitochondrial differences between sexes can give particularly useful insights to predict the development of hypertension later in life. In this regard, male subjects seem disadvantaged in the mitochondrial background, presenting lower content of several mitochondrial transcripts (Fig. $2 A$ ), suggesting hormone-dependent effects.
Sex dissimilarities in the progression of various renal diseases have been reported in animal and humans studies, with men at higher risk of developing renal diseases, with the tendency to develop it earlier in life and with a faster progression and deterioration of renal function than in women $(22,23$, $27,33,51,54)$. Apart from the genetically coded dissimilarities between the sexes in renal structure and function, sex hormones may affect several of the routes implicated in the pathogenesis of renal disease development. Possible mechanisms include receptor-mediated effects of sex hormones on glomerular hemodynamics and cell proliferation as well as effects on the synthesis and release of cytokines, vasoactive agents, and growth factors. In addition, estrogens can also provide a protective effect in female subjects due to their antioxidant action (57).

Some studies concerning MNR have reported complementary results to our findings. For example, in term rat placentas, mitochondrial abnormalities were observed with reduced ATP levels found, despite increased mitochondrial biogenesis and activity (40). Using a maternal low-protein diet rat model, the expression of malate dehydrogenase, as well as the mitochondrial DNA-encoded subunit 6 of ATP synthase, was lower in the pancreatic islets, reducing the capacity of ATP production through mitochondrial oxidative metabolism. Interestingly, in agreement with our results, several consequences of protein restriction during fetal life were more marked in male offspring (60).

There is ample evidence that the intrauterine environment is extremely important for the future health of the individual. This has been shown for cardiovascular diseases, hypertension, obesity, type 2 diabetes, and metabolic syndrome as well as renal diseases, such as albuminuria and chronic kidney disease $(5,9)$.

Final conclusions. The findings presented here, for the first time, demonstrate the tissue-specific nature of mitochondrial protein development that may reflect differences in functional adaptation after birth. The divergence in mitochondrial responses between tissues to maternal nutrient manipulations early in pregnancy further reflects these differential ontogenies.

It is also tempting to speculate that, by defining and delivering optimal maternal nutrition during critical time windows during fetal development, long-term health benefits for offspring can be achieved.

\section{ACKNOWLEDGMENTS}

The authors acknowledge contributions by Paulina Quezada, Greg Langone, and Li Cun for immunohistochemistry, by Michelle Zavala for technical assistance in the laboratory, by Leslie Myatt, Alina Maloyan, Nagarjun Kasaraneni, Chunming Guo, Balasubashini Muralimanoharan, and James Mele by allowing access to equipment, and finally by Karen Moore and Susan Jenkins for bibliography and data archiving.

\section{GRANTS}

This work was supported by National Institutes of Health (NIH) Grant PO1 HD021350 (to P. W. Nathanielsz, M. J. Nijland, and L. A. Cox), Fundação Montepio Geral and Fundação Para a Ciência e a Tecnologia (FCT), Portugal for the PhD fellowship SFRH/BD/64247/2009 (to S. P. Pereira) and for the core research grant PEst-C/SAU/LA0001/2013-2014 (C. N. C). This investigation also used resources and facilities which were supported by Southwest National Primate Research Center Grant P51 RR013986 from the National Center for Research Resources, NIH and which are currently supported by the Office of Research Infrastructure Programs through P51 OD011133 and C06 RR013556.The funding agencies had no role in study design, data collection and analysis, decision to publish, or preparation of the manuscript. 


\section{DISCLOSURES}

No conflicts of interest, financial or otherwise, are declared by the author(s).

\section{AUTHOR CONTRIBUTIONS}

Author contributions: S.P.P. performed experiments; S.P.P. and L.C.T analyzed data; S.P.P. and L.C.T. interpreted results of experiments; S.P.P. prepared figures; S.P.P. drafted manuscript; S.P.P., P.J.O., L.C.T., A.J.M., L.A.C., P.W.N., and M.J.N. approved final version of manuscript; P.J.O., P.W.N., and M.J.N. conception and design of research; P.J.O., A.J.M., L.A.C., P.W.N., and M.J.N. edited and revised manuscript.

\section{REFERENCES}

1. Antonow-Schlorke I, Schwab M, Cox LA, Li C, Stuchlik K, Witte OW, Nathanielsz PW, McDonald TJ. Vulnerability of the fetal primate brain to moderate reduction in maternal global nutrient availability. Proc Natl Acad Sci USA 108: 3011-3016, 2011.

2. Armitage J, Lakasing L, Taylor P, Balachandran A, Jensen R, Dekou V, Ashton N, Nyengaard J, Poston L. Developmental programming of aortic and renal structure in offspring of rats fed fat-rich diets in pregnancy. J Physiol 565: 171-184, 2005.

3. Assis T, Melo E, Filho JA. Effects of intrauterine malnutrition on the renal morphology of Wistar rats: a systematic review. J Morphol Sci 28: $1-3,2011$.

4. Balaban RS, Nemoto S, Finkel T. Mitochondria, oxidants, and aging. Cell 120: 483-495, 2005.

5. Barker DJ, Lampl M, Roseboom T, Winder N. Resource allocation in utero and health in later life. Placenta 33, Suppl 2: e30-e34, 2012.

6. Benz K, Amann K. Maternal nutrition, low nephron number and arterial hypertension in later life. Biochim Biophys Acta 1802: 1309-1317, 2010.

7. Bouret SG, Simerly RB. Developmental programming of hypothalamic feeding circuits. Clin Genet 70: 295-301, 2006.

8. Choi J, Li C, McDonald TJ, Comuzzie A, Mattern V, Nathanielsz PW. Emergence of insulin resistance in juvenile baboon offspring of mothers exposed to moderate maternal nutrient reduction. Am J Physiol Regul Integr Comp Physiol 301: R757-R762, 2011.

9. Chong E, Yosypiv IV. Developmental programming of hypertension and kidney disease. Int J Nephrol 2012: 760580, 2012.

11. Cox LA, Nijland MJ, Gilbert JS, Schlabritz-Loutsevitch NE, Hubbard GB, McDonald TJ, Shade RE, Nathanielsz PW. Effect of 30 per cent maternal nutrient restriction from 0.16 to 0.5 gestation on fetal baboon kidney gene expression. J Physiol 572: 67-85, 2006.

12. Cummins JM. The role of mitochondria in the establishment of oocyte functional competence. Eur J Obs Gynecol Reprod Biol Suppl 115: S23-S29, 2004.

13. Dallman MF, Akana SF, Pecoraro NC, Warne JP, la Fleur SE, Foster MT. Glucocorticoids, the etiology of obesity and the metabolic syndrome. Curr Alzheimer Res 4: 199-204, 2007.

14. DiMauro S, Schon EA. Mitochondrial respiratory-chain diseases. $N$ Engl J Med 348: 2656-2668, 2003.

15. Drever N, McDonald T, Nathanielsz P, Li C. IGF-II and insulin (ins) are decreased in the baboon fetal pancreas in response to global $30 \%$ maternal nutrient restriction (MNR) (Abstract). Reprod Sci 15: 122A, 2008.

16. Dumollard R, Duchen M, Carroll J. The role of mitochondrial function in the oocyte and embryo. Curr Top Dev Biol 77: 21-49, 2007.

17. Engeham S, Mdaki K, Jewell K, Austin R, Lehner AN, Langley-Evans SC. Mitochondrial respiration is decreased in rat kidney following fetal exposure to a maternal low-protein diet. J Nutr Metab 2012: 989037 , 2012.

18. Fedorova LV, Tamirisa A, Kennedy DJ, Haller ST, Budnyy G, Shapiro JI, Malhotra D. Mitochondrial impairment in the five-sixth nephrectomy model of chronic renal failure: proteomic approach. $B M C$ Nephrol 14: 209, 2013.

19. Fernandes MA, Pereira SP, Jurado AS, Custódio JB, Santos MS, Moreno AJ, Duburs G, Vicente JA. Comparative effects of three 1,4-dihydropyridine derivatives [OSI-1210, OSI-1211 (etaftoron), and OSI-3802] on rat liver mitochondrial bioenergetics and on the physical properties of membrane lipid bilayers: relevance to the length of the alkoxyl chain in positions 3 and 5 of the DHP ring. Chem Biol Interact 173: 195-204, 2008.

20. Ferré P, Burnol AF, Leturque A, Terretaz J, Penicaud L, Jeanrenaud B, Girard J. Glucose utilization in vivo and insulin-sensitivity of rat brown adipose tissue in various physiological and pathological conditions. Biochem J 233: 249-252, 1986.
21. Fowden AL, Giussani a D, Forhead AJ. Endocrine and metabolic programming during intrauterine development. Early Hum Dev 81: 723734, 2005.

22. Gilbert JS, Nijland MJ. Sex differences in the developmental origins of hypertension and cardiorenal disease. Am J Physiol Regul Integr Comp Physiol 295: R1941-R1952, 2008.

23. Gretz N, Zeier M, Geberth S, Strauch M, Ritz E. Is gender a determinant for evolution of renal failure? A study in autosomal dominant polycystic kidney disease. Am J Kidney Dis 14: 178-183, 1989.

24. Heyman SN, Rosenberger C, Rosen S. Acute kidney injury: lessons from experimental models. Contrib Nephrol 169: 286-296, 2011.

25. Honzik T, Wenchich L, Böhm M, Hansikova H, Pejznochova $M$, Zapadlo M, Plavka R, Zeman J. Activities of respiratory chain complexes and pyruvate dehydrogenase in isolated muscle mitochondria in premature neonates. Early Hum Dev 84: 269-276, 2008.

26. Hughson M, Farris AB, Douglas-Denton R, Hoy WE, Bertram JF. Glomerular number and size in autopsy kidneys: the relationship to birth weight. Kidney Int 63: 2113-2122, 2003.

27. Iseki K, Ikemiya Y, Kinjo K, Inoue T. Body mass index and the risk of development of end-stage renal disease in a screened cohort. Kidney Int 65: 1870-1876, 2004.

28. Keenan $\mathbf{K}$, Bartlett $\mathbf{T}$, Nijland $\mathbf{M}$, Rodriguez $\mathbf{J}$, Nathanielsz $\mathbf{P}$, Zürcher N. Poor nutrition during pregnancy and lactation negatively affects neurodevelopment of the offspring: evidence from a translational primate model. Am J Clin Nutr 98: 396-402, 2013.

29. Keller G, Zimmer G, Mall G. Nephron number in patients with primary hypertension. N Engl J Med 348: 101-108, 2003.

30. Lebrecht D, Setzer B, Ketelsen UP, Haberstroh J, Walker UA. Timedependent and tissue-specific accumulation of mtDNA and respiratory chain defects in chronic doxorubicin cardiomyopathy. Circulation 108: 2423-2429, 2003.

31. Li C, McDonald T, Wu G, Nijland M, Nathanielsz P. Intrauterine growth restriction alters term fetal baboon hypothalamic appetitive peptide balance. J Endocrinol 217: 275-282, 2013.

32. Li C, Schlabritz-Loutsevitch NE, Hubbard GB, Han V, Nygard K, Cox LA, McDonald TJ, Nathanielsz PW. Effects of maternal global nutrient restriction on fetal baboon hepatic insulin-like growth factor system genes and gene products. Endocrinology 150: 4634-4642, 2009.

33. Li S, Chen SC, Shlipak M, Bakris G, McCullough PA, Sowers J, Stevens L, Jurkovitz C, McFarlane S, Norris K, Vassalotti J, Klag MJ, Brown WW, Narva A, Calhoun D, Johnson B, Obialo C, WhaleyConnell A, Becker B, Collins AJ. Low birth weight is associated with chronic kidney disease only in men. Kidney Int 73: 637-642, 2008.

34. Lin MT, Beal MF. Mitochondrial dysfunction and oxidative stress in neurodegenerative diseases. Nature 443: 787-795, 2006.

35. Lucas SR, Zaladek-Gil F, Costa-Silva VL, Miraglia SM. Function and morphometric evaluation of intrauterine undernutrition on kidney development of the progeny. Braz J Med Biol Res 24: 967-970, 1991.

36. Luyckx V, Brenner B. Low birth weight, nephron number, and kidney disease. Kidney Int 68: 68-77, 2005.

37. Luyckx V, Shukha K, Brenner B. Low nephron number and its clinical consequences. Rambam Maimonides Med J 2: 1-16, 2011.

38. Machado NG, Baldeiras I, Pereira GC, Pereira SP, Oliveira PJ. Sub-chronic administration of doxorubicin to Wistar rats results in oxidative stress and unaltered apoptotic signaling in the lung. Chem Biol Interact 188: 478-486, 2010.

39. Magyar DM, Fridshal D, Elsner CW, Glatz T, Eliot J, Klein AH, Lowe KC, Buster JE, Nathanielsz PW. Time-trend analysis of plasma cortisol concentrations in the fetal sheep in relation to parturition. Endocrinology 107: 155-159, 1980.

40. Mayeur S, Lancel S, Theys N, Lukaszewski MA, Duban-Deweer S, Bastide B, Hachani J, Cecchelli R, Breton C, Gabory A, Storme L, Reusens B, Junien C, Vieau D, Lesage J. Maternal calorie restriction modulates placental mitochondrial biogenesis and bioenergetic efficiency: putative involvement in fetoplacental growth defects in rats. Am J Physiol Endocrinol Metab 304: E14-E22, 2013.

41. Merlet-Bénichou C, Vilar J, Lelievre-Pegorier M, Moreau E, Gilbert T. Fetal nephron mass: its control and deficit. Adv Nephrol Necker Hosp 26: $19-45,1997$.

42. Moritz KM, Cuffe JS, Wilson LB, Dickinson H, Wlodek ME, Simmons DG, Denton KM. Review: Sex specific programming: a critical role for the renal renin-angiotensin system. Placenta Suppl 31: S40-S46, 2010.

43. Moritz KM, Wintour EM. Functional development of the meso- and metanephros. Pediatr Nephrol 13: 171-178, 1999. 
44. Nijland MJ, Mitsuya K, Li C, Ford S, McDonald TJ, Nathanielsz PW, Cox LA. Epigenetic modification of fetal baboon hepatic phosphoenolpyruvate carboxykinase following exposure to moderately reduced nutrient availability. J Physiol 588: 1349-1359, 2010.

45. Nijland MJ, Schlabritz-Loutsevitch NE, Hubbard GB, Nathanielsz PW, Cox LA. Non-human primate fetal kidney transcriptome analysis indicates mammalian target of rapamycin (mTOR) is a central nutrientresponsive pathway. J Physiol 579: 643-656, 2007.

47. Osmond C, Barker DJ. Fetal, infant, and childhood growth are predictors of coronary heart disease, diabetes, and hypertension in adult men and women. Environ Health Perspect 108: 545-553, 2000.

48. Pereira GC, Pereira SP, Pereira CV, Lumini a J, Magalhães J, Ascensão A, Santos MS, Moreno AJ, Oliveira PJ. Mitochondrionopathy phenotype in doxorubicin-treated Wistar rats depends on treatment protocol and is cardiac-specific. PLos One 7: e38867, 2012.

49. Pereira SP, Fernandes MA, Martins JD, Santos MS, Moreno AJ, Vicente AJ, Videira RA, Jurado AS. Toxicity assessment of the herbicide metolachlor comparative effects on bacterial and mitochondrial model systems. Toxicol Vitr 23: 1585-1590, 2009.

50. Pereira SP, Pereira GC, Pereira CV, Carvalho FS, Cordeiro MH, Mota PC, Ramalho-Santos J, Moreno AJ, Oliveira PJ. Dioxin-induced acute cardiac mitochondrial oxidative damage and increased activity of ATP-sensitive potassium channels in Wistar rats. Env Pollut 180: 281-290, 2013.

51. Reyes D, Lew SQ, Kimmel PL. Gender differences in hypertension and kidney disease. Med Clin North Am 89: 613-630, 2005.

52. Rincon-Choles H, Abboud HE, Lee S, Shade RE, Rice KS, Carey KD, Comuzzie AG, Barnes JL. Renal histopathology of a baboon model with type 2 diabetes. Toxicol Pathol 40: 1020-1030, 2012.

53. Rogers J, Hixson JE. Baboons as an animal model for genetic studies of common human disease. Am J Hum Genet 61: 489-493, 1997.

54. Sakemi T, Toyoshima H, Morito F. Testosterone eliminates the attenuating effect of castration on the progressive glomerular injury in hypercholesterolemic male Imai rats. Nephron 67: 469-476, 1994.

55. Schlabritz-Loutsevitch NE, Howell K, Rice K, Glover EJ, Nevill CH, Jenkins SL, Bill Cummins L, Frost PA, McDonald TJ, Nathanielsz
PW. Development of a system for individual feeding of baboons maintained in an outdoor group social environment. J Med Primatol 33: 117-126, 2004.

56. Schlabritz-Loutsevitch NE, Hubbard GB, Dammann MJ, Jenkins SL, Frost PA, McDonald TJ, Nathanielsz PW. Normal concentrations of essential and toxic elements in pregnant baboons and fetuses (Papio species). J Med Primatol 33: 152-162, 2004.

57. Silbiger SR, Neugarten J. The impact of gender on the progression of chronic renal disease. Am J Kidney Dis 25: 515-533, 1995.

58. Szendroedi J, Phielix E, Roden M. The role of mitochondria in insulin resistance and type 2 diabetes mellitus. Nat Rev Endocrinol 8: 92-103, 2012.

59. Tachibana M, Sparman M, Sritanaudomchai H, Ma H, Clepper L, Woodward J, Li Y, Ramsey C, Kolotushkina O, Mitalipov S. Mitochondrial gene replacement in primate offspring and embryonic stem cells. Nature 461: 367-372, 2009.

60. Theys N, Bouckenooghe T, Ahn MT, Remacle C, Reusens B. Maternal low-protein diet alters pancreatic islet mitochondrial function in a sexspecific manner in the adult rat. Am J Physiol Regul Integr Comp Physiol 297: R1516-R1525, 2009.

61. Turkkan JS, Goldstein DS. Chronic effects of high salt intake and conflict stress on blood pressure in primates. A progress report. Integr Physiol Behav Sci 26: 269-81, 1991.

62. White SL, Perkovic V, Cass A, Chang CL, Poulter NR, Spector T, Haysom L, Craig JC, Salmi IA, Chadban SJ, Huxley RR. Is low birth weight an antecedent of CKD in later life? A systematic review of observational studies. Am J Kidney Dis 54: 248-261, 2009.

63. Wyrwoll CS, Mark PJ, Waddell BJ. Developmental programming of renal glucocorticoid sensitivity and the renin-angiotensin system. Hypertension 50: 579-584, 2007.

64. Zohdi V, Sutherland MR, Lim K, Gubhaju L, Zimanyi MA, Black MJ. Low birth weight due to intrauterine growth restriction and/or preterm birth: effects on nephron number and long-term renal health. Int J Nephrol 2012: 136942, 2012

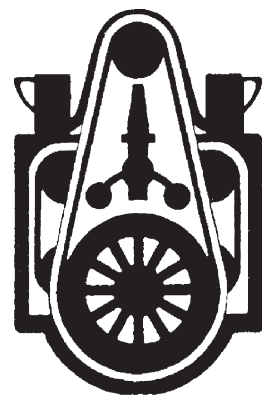

